\title{
The Impact of Near-Death Experiences on Persons Who Have Not Had Them: A Report of a Preliminary Study and Two Replications
}

\author{
Kenneth Ring, Ph.D. \\ University of Connecticut
}

ABSTRACT. Three informal surveys of college students enrolled in a semester-long course on near-death experiences (NDEs) suggest that exposure to information about the NDE may bring about substantial changes in beliefs about NDEs, life after death, and God, as well as reduce fear of death and increase one's level of spirituality. These surveys and previous research point to the importance of conducting more systematic and large-scale studies of the impact of NDE materials on the general population.

It's curious that for all the work that has so far been reported on the effects of near-death experiences (NDEs) on the experiencers themselves (e.g., Ring, 1980, 1984; Grey, 1985; Flynn, 1986; Atwater, 1988; Sutherland, 1992; Morse and Perry, 1992; Tiberi, 1993), there has been almost nothing published in the literature concerning how nonexperiencers are affected by their exposure to information about NDEs. The lack of systematic research on this matter is even more surprising in view of two obvious considerations: (1) after nearly two decades of reports about NDEs and the enormous publicity they have received through the mass media, especially in the Western world, it is certainly reasonable to think that all this information must have

Kenneth Ring, Ph.D., is Professor Emeritus of Psychology at the University of Connecticut. Reprint requests should be addressed to Dr. Ring at the Department of Psychology, University of Connecticut, U-20, 406 Babbidge Road, Storrs, CT 06269. 1020. 
had a significant impact on humanity's understanding of the nature of death; and (2) most of the earth's population is made up of persons who have not had an NDE. The fact that after all this time we still know so very little about how most of the world has actually responded to this tremendous volume of NDE-based material now available is surely a striking lacuna in the field of near-death studies, which, one hopes, researchers would be eager to fill.

Of course, it would be misleading to imply that we don't have some data bearing on this issue. There have already been, for example, a number of surveys of various professional groups, such as physicians, nurses, psychologists, or members of the clergy, in the United States (e.g., Royse, 1985; Orne, 1986; Walker and Russell, 1989; Hayes and Waters, 1989; Barnett, 1991; Bechtel, Chen, Pierce, and Walker, 1992; Moore, 1994) or of selected communities elsewhere (e.g., Kellehear and Heaven, 1989; Kellehear, Heaven and Gao, 1990) that have inquired into their knowledge and acceptance of NDEs. And there are naturally a scattering of published letters, such as those of Deborah Drumm (1992, 1993), that have provided eloquent and moving testimony of the power of NDE literature to provide comfort, hope, and inspiration to individuals who have not themselves had these experiences. These surveys and personal accounts are certainly suggestive of the impact that information about NDEs may have on selected groups and individuals, but they are still a long way from careful studies directed to the question of how such information has been received by the population at large.

In fact, there are only two studies I am familiar with that have consciously attempted to explore this question, albeit with samples of nonexperiencers that are still very far from being representative of people in general. The first of these was described a few years ago by the late sociologist Charles Flynn in his book After the Beyond (1986) and was called "The Love Project." This undertaking represented Flynn's attempt to drive home some of the moral lessons of the NDE by asking the students in his sociology classes at Miami University of Ohio to make a specific semester-long effort "to relate in a loving manner to someone they wouldn't otherwise relate to" (Flynn, 1986, p. 7). As a guide for such action, Flynn required his students to read a then popular book by Leo Buscaglia, Love (1982), and showed them videos of Buscaglia's lectures. Although his courses were not primarily concerned with NDEs, Flynn also discussed them, emphasizing how such experiences tend to lead to a more loving and 
compassionate attitude toward others, and played videos featuring NDErs.

Altogether, 428 students took part in these "Love Projects." Flynn evaluated the results of his students' activities through a combination of questionnaires and personal journals. His findings showed strong evidence that these interactions resulted in an increased sense of compassionate concern for others in general (more than 80 percent of his students reported this effect) as well as greater feelings of their own self worth (indicated by about 65 percent of these students). Furthermore, these effects tended to persist, though with some diminishment, as shown by a follow-up survey a year later.

Of course, this attempt to foster "the lessons of love stemming from the NDE," as Flynn (1986, p. 7) unabashedly put it, goes well beyond simply examining the effects of mere exposure to NDE information, which is what I am chiefly concerned with here. Nevertheless, more recent research suggests it is by no means necessary to induce persons to become involved in an applied way in order for them to reap some of the benefits of NDEs for themselves. Apparently, at least for persons who are open to or become interested in NDEs, simple exposure may be sufficient to bring about the same kind of changesand more - that Flynn found characteristic of his students.

Here I am alluding to some recent work of my own which I have already described in a couple of places (Ring and Rosing, 1990; Ring, 1992) under the title of "The Omega Project." The relevant part of that study involved 74 NDErs and, especially pertinent here, a control group of 54 persons who were known to be interested in NDEs but had never had such an experience themselves. In examining the pattern of belief and value changes, we found that the control group showed many of the same effects as NDErs since becoming interested in NDEs, though, not surprisingly, the magnitude of these changes was usually somewhat less than for the NDErs themselves. Specifically, the mean (statistically significant) shifts for the controls demonstrated that they also had become more appreciative of life, more self-accepting, more compassionately concerned for others, more spiritual, less materialistic, and so on-in short, that they tended to have the same kind of value profile as actual NDErs, presumably just as a result of finding themselves drawn to the world of these experiences.

Moreover, there are other changes they reported that are similar to the views of NDErs. For example, like NDErs, the great majority of the controls also evinced an increased ecological sensitivity and a 
greater planetary concern following their exposure to NDE materials. Furthermore, more than 80 percent of the controls indicated a diminished fear of death, and a like percentage affirmed that their belief in life after death had increased - effects that again are typical of those described by NDErs. In general, the overall pattern of our comparative data here hinted strongly that the NDE may be a contagious experience, at least to those who are or come to be receptive to it; people can apparently "catch" the effects through exposure, direct or otherwise, to those who have had the encounter themselves.

These findings, and especially their implications, have come to intrigue me and, as I have already argued, warrant further attention on the part of researchers. As a preliminary effort toward this end, I conducted an informal study, which has now been replicated twice, that combines facets of Flynn's approach with something of the methodology of The Omega Project. It is the purpose of this brief report simply to describe this research, but with the underlying aim of encouraging other investigators to undertake the larger, more systematic type of work I implicitly called for at the very beginning of this article. What follows, then, is merely another suggestive line of inquiry that points again to our need, finally and fully, to understand the impact of information about NDEs on the population at large.

\section{Evaluating the Effects of an Academic Course on the NDE: The Initial Survey}

From 1985 to 1994, I offered an undergraduate course on the NDE at the University of Connecticut. Eventually given every semester, it normally had an enrollment of about 35 to 40 students, and over the years I have had probably close to 500 students in it. In this course, I required my students to maintain an extensive journal in which they recorded their reactions to and commentaries upon the classes, the assigned reading, and events in their lives or others that bore on the topics we considered during the semester. In reading these journals and my students' term papers, as well as from discussions with them, I often had cause to be aware that the course, by and large, tended to have a pronounced, and in quite a few cases I would say quite obviously deep, impact on my students. Still, I was reluctant to attempt to assess these changes in any careful, rigorous way lest I be perceived as having some kind of hortatory interest in teaching this course. Indeed, I was at pains at the beginning of the 
semester to welcome and invite all points of view, including the rankest form of skepticism, and simply invited my students to consider the material I presented in a spirit of open-minded inquiry through which to reach their own conclusions about the NDE.

What was actually presented in the course? Because it will be relevant to the study reported below, let me give a brief description of the class. We began by my giving an overview of the NDE itself and then seeing some videos of persons narrating their NDEs. This was followed by three NDErs coming to class to share their own experiences directly with the students. Occasionally throughout the semester, I would break up the students into small groups to discuss among themselves issues we were dealing with in the course, and I always did this first in the class following the visit from the NDErs. Eventually, we went on to review what we now know about NDEs and various interpretative models that have been offered to explain the experience, along the way considering such topics as veridicality studies, NDEs in children, frightening NDEs, suicide and NDEs, cross-cultural research, and so on.

In the second half of the course, I presented material on other phenomena related to NDEs, such as deathbed visions, OBEs, and mystical experiences, and then devoted a portion of the course to an examination of the aftereffects of NDEs. Toward the end of the course, there was some but not a lot of consideration given to larger, speculative questions suggested by NDEs and their possible evolutionary implications. During the semester, I would bring to class at least three more NDErs, usually to discuss aftereffects, and other guest speakers, including researchers. I also conducted a limited number-usually two- of experiential classes for which, for example, I had designed exercises that asked students to confront their own death or ponder the implications of the life review for their own lives. Altogether, we met 28 times over a period of 14 weeks, with each class lasting approximately 75 minutes.

For reading, I assigned Raymond Moody's Life After Life (1975), my own Heading Toward Omega (1984), one of the late Scott Rogo's books, Life After Death (1986) (mainly for its discussion of various parapsychological phenomena related to NDEs; the subject of life after death itself is only discussed in passing and is not at all a major theme of the course), and the last book of another recently deceased writer, Michael Talbot, called The Holographic Universe (1991). This book provides a unifying theoretical perspective based on certain ideas in physics and the neurosciences that attempts to show how 
anomalies such as NDEs may possibly be understood within a "New Paradigm" science approach. (Unfortunately, this book has proved too difficult for a significant number of my students and perhaps as many as half of them didn't seem to get much out of it-or, in some cases, even read it in the first place!)

What kind of student was it that ended up in this course? I conducted an informal survey at the beginning to find out, just to see what these students might already know about NDEs and what their view of them was. Generally speaking these students, almost always juniors or seniors, didn't know a great deal about NDEs, and most of what they did know seemed to be based on the expected unreliable or sensationalistic sources, such as talk shows, tabloids, magazine articles, and films. Thus, as a rule, they had a shallow, usually superficial acquaintance with the NDE to start with. Most of these students were open to it, however, and expressed curiosity to learn more. Strong skeptics or outright debunkers were relatively rare (though I had them), but a fair number of students did express some degree of skepticism or other forms of reservation at the beginning of the semester.

My impression-admittedly, I haven't taken the trouble to check this out by examining their academic records-is that, on the whole, I got somewhat more than my share of bright and serious students in this course, though I certainly had a measure of the other kind, too. In short, these students, while obviously self-selected and generally talented, were by no means "true believers" at the beginning of the course nor were they particularly knowledgeable about NDEs. As a group, they could be characterized, then, at the outset of the course as interested in and curious about the phenomenon.

The question is, how did this course affect them, and, secondarily, exactly what affected them during their progression through the semester?

I have already said that, previously, I had been reluctant to inquire into this matter for fear of appearing invested in the outcome. Accordingly, I had simply noted for myself over the years that many students gave clear indications that the course had had a strong and positive effect on them. In the spring semester of 1993 , however, as I was pondering the issue of the impact of NDEs based on the findings of the Omega Project, I decided, on the spur of the moment, to ask my students to fill out a little questionnaire for me at the very end of the course (that I had concocted just the day before). Thus, 
they didn't know that this self-assessment was coming, and I certainly hadn't planned it. The results of this informal ad hoc survey will be presented next.

\section{Results of the Initial Survey}

Twenty-eight students happened to be in class the day I administered the survey. The survey itself consisted of eight sets of multiple-choice statements, all of which began with the stem, "As a result of taking this course . ..." and two open-ended questions. Students were asked in written instructions to answer anonymously and as truthfully as possible.

The first statement dealt with the authenticity of NDEs. Twentyseven of the twenty-eight students (96 percent) said they were now more convinced of the authenticity of NDEs, while one person's opinion was unchanged. When one recalls that most of these students were open to NDEs in the first place and certainly many of them inclined at the beginning of the semester to think that the NDE was a legitimate experience, the fact that their sense of the authenticity of the NDE increased almost universally is even more noteworthy.

The second statement concerned their fear of death. Twenty students ( 71 percent) reported it decreased, while eight said it was unchanged. Likewise, 23 students (82 percent) affirmed they now had a more positive view of death, while no one saw it more negatively.

The next item inquired about whether students believed in "some form of conscious existence following physical death." Again, 23 students ( 82 percent) stated that they were now more convinced of this, while the remainder showed no change of opinion. Once more, it is worth noting that though this subject was discussed in some of the assigned books, it was not a salient issue in the classes themselves.

The next topic was reincarnation, something that again was not discussed, except in passing one day in class, but is mentioned briefly both in Heading Toward Omega (Ring, 1984) and The Holographic Universe (Talbot, 1991). Despite the lack of emphasis given to this matter, 15 students (54 percent) stated they were more open to it, whereas only one moved in the opposite direction.

Seventeen students ( 61 percent) felt as a result of taking the course that they were more spiritually oriented individuals, while the remainder was unchanged in this respect; and 19 students (68 percent) 
were more convinced that their own life had a purpose, while all but one of the remainder were unchanged.

Finally, 20 students (71 percent) said that their ideas about God had changed as a result of the course, including eight students (29 percent) who specifically stated that their belief in God had been strengthened. No one reported that his or her belief in God had been weakened, though another eight students (29 percent) stated that their ideas about God went unchanged.

Some further insight into the specifics of this last item can be gleaned from examining students' responses to the first of the two open-ended questions that followed. That question, preceded by a statement, was: "Many NDErs have talked about their encounter with 'the Light.' What do you personally understand 'the Light' to be?"

As I perused the students' responses to this question, their answers, I found, tended to cluster around three words: "God," "energy," and "everything"! I could probably best give a sense of the general tendency of their comments here by simply using the phrase, "the Light is It!" Still, it would presumably be more helpful if I were at least to quote a few students specifically on this point to illustrate these interpretations.

Said one: "Everything. I see the light as being part of everything and that all life is connected."

Another replied: "I believe the Light is God, the one true God."

Still another said: "I understand 'the Light' to be unconditional love. It is the equivalent of 'God' but is not a religious figure. 'The Light' is spiritual in nature and serves to deliver good to those who encounter it .... We are all a part of it."

And a final comment: "I think 'the Light' is the energy of life all encompassed into one being-and that is all the goodness of the world."

The last question read, "What, for you, are the most important things you gained from your study of the NDE this semester?"

Here, not surprisingly, the responses seemed to cover a wide spectrum, but two tendencies predominated. One was a feeling that one had somehow become "a better person"; the other related to a deepened conviction concerning life after death. Four examples to illustrate these themes again follow:

I have found a spirituality that has been hiding within myself. I see how I affect others more and I want to let this new spirituality grow over time. 
I have felt a feeling of being set free from much of the negative aspects of life. I have gained some profound self-knowledge and an increased sense of self-worth. I have become more appreciative of life and love .... I feel this course has been extremely helpful in my life.

I have less negative feelings about death because I strongly believe in the light and the afterlife.

The most important things I have gained from the NDE is that there is life after death, it is a peaceful place, and we should not be afraid to die.

\section{Results of Two Replications of the Survey}

Since the initial study described above, there have been two independent replications of these findings worth summarizing here. One of these again involved a survey of my own NDE course, taught in the fall of 1993; the other was based on a very similarly structured NDE course taught by Victoria Young at Montana State University during the same (fall 1993) semester.

In general the results of these independent studies were quite similar to those reported above. Here, however, I will merely take the time to present the statistical findings for the eight multiple choice items (see Table 1). To afford easy and simple comparisons, I will first list the percentages for the original spring 1993 survey and then those for the same items for the two replications.

As can be seen, the results of my two surveys and that of Young are in general quite consistent across all items, with the possible exception of that pertaining to reincarnational beliefs, where the replications showed a somewhat lower level of openness to such beliefs.

One final comment worth noting is that in my fall $1993 \mathrm{NDE}$ course, more than half the students elected to read a skeptically oriented book on NDEs, Susan Blackmore's Dying to Live (1993). This book presented a materialistic and reductionistic interpretation of the NDE, which asserted that the NDE offers no evidence for a life after death, whose existence Blackmore emphatically denied in any case. Wondering whether the students who chose to read Blackmore's book might have been affected differently by the course, I examined their survey data separately after tabulating the results for the class as a whole. Interestingly, these students responded in exactly the same manner as did those who did not read Blackmore's book. This was 


\section{Table 1}

Percent of Students in NDE Courses Reporting Changes in Attitudes and Beliefs

\begin{tabular}{cccc}
\hline & UConn & UConn & MSU \\
Spring 1993 & Fall 1993 & Fall 1993 \\
Item & $(n=28)$ & $(n=28)$ & $(n=45)$ \\
\hline
\end{tabular}

Belief in authenticity of NDE:

\begin{abstract}
increase
decreased
\end{abstract}

no change

Fear of death:

increased

decreased

no change

View of death:

more positive

less positive

no change

Belief in life after death:

increased

decreased

no change

Openness to reincarnation:

more open

less open

no change

Spiritual orientation:

increased

decreased

no change

Belief in God:

increased

decreased

other change

no change

Belief in purposefulness of life:

increased

decreased

no change
96

0

4

0

71

29

82

0

18

82

0

18

54

4

43

61

0

39

29

0

43

29

68

4

29
90

0

96

10

2

2

0

71

29

$36 \quad 29$

$90 \quad 82$

$0 \quad 0$

$10 \quad 18$

90

76

0

10

0

24

$29 \quad 38$

$7 \quad 9$

$64 \quad 53$

57

64

0

2

$43 \quad 33$

29

36

4

2

54

27

$14 \quad 36$

\section{9}

8


true despite the fact that those reading this book overwhelmingly recommended that I continue to use it.

\section{Discussion}

Despite the small self-selected nature of the sample and the ad hoc character of these surveys, there is one general finding that shines forth from these studies that is undeniable: These students expressed sentiments, feelings, values and beliefs that are indistinguishable from those commonly uttered by NDErs themselves. The same effects that NDErs tend to attribute to their experience these students indicated derived from their exposure to their course on NDEs. If one takes these statements at face value just for the moment, it is as if the benefits of the NDE can be transmitted vicariously (at least to such persons) simply by exposing individuals to materials on the subject. The two replications provide more evidence for the power of the NDE to affect in positive ways those who are enrolled in courses on the subject, even when countervailing information and skeptical viewpoints are presented. The implications are obviously profound.

But before we soar too high into the world of exciting possibility, let us quickly ground ourselves with the necessary weight of caution. Of course we cannot blithely take these statements at face value. We don't know, for instance, how indicative of deep-lying changes they really may be, how long-lasting they are even if sincere, and to what extent the responses of these students may have been influenced by the demand characteristics (Orne, 1962) of the situation. And even if these changes proved to be lasting and in some ways comparable to those that NDErs have shown, we don't have any real idea what specific features of the course may have been responsible for them. For example, I have a strong suspicion that the single most important influence in shaping students' reactions was the direct inclass appearance of the NDErs themselves. One could, indeed, continue to raise a host of interpretative questions of this kind-and should-before making too much of these paltry, if intriguing, data.

But that is just the point and moral of these surveys and my brief commentary upon them. We have here a clue, as tantalizing as it is inconclusive, of the power of exposure to NDE material to affect persons in ways similar to that of the NDE itself. Furthermore, the 
findings here, though we must have deep reservations about their reliability and generalizability, are at least consistent with the previously mentioned research on the question.

The promise of this kind of research, as well as its challenge, is obvious and, to me at least, it seems clear that this must be a new direction for work in the field of near-death studies, particularly for investigators skilled in survey methods. Why not at least a Gallup or Roper poll on the subject, just for openers? Aren't many of us really curious to know, after all this time, precisely how people across the world have been affected by all this information on the NDE, and how we might better design programs of NDE education to optimize these effects, if this is our goal?

These student surveys have scarce value in themselves except as a reminder of and a goad for what could be accomplished if researchers were to turn their attention at long last to NDE impact studies. This article is submitted with the hope that the small seed it represents will yield in time a large and bountiful harvest.

\section{References}

Atwater, P. M. H. (1988). Coming back to life: The after-effects of the near-death experience. New York, NY: Dodd, Mead.

Barnett, L. (1991). Hospice nurses' knowledge and attitudes toward the near-death experience. Journal of Near-Death Studies, 9, 225-232.

Bechtel, L. J., Chen, A., Pierce, R. A., and Walker, B. A. (1992). Assessment of clergy knowledge and attitudes toward near-death experiences. Journal of Near-Death Studies, 10, 161-170.

Blackmore, S. (1993). Dying to live: Science and the near-death experience. Buffalo, NY: Prometheus.

Buscaglia, L. (1982). Love. New York, NY: Fawcett.

Drumm, D. L. (1992). Near-death accounts as therapy [Letter]. Journal of Near-Death Studies, 11, 67-70.

Drumm, D. L. (1993). Near-death accounts as therapy: Part II [Letter]. Journal of Near-Death Studies, 11, 189-191.

Flynn, C. P. (1986). After the beyond: Human transformation and the near-death experience. Englewood Cliffs, NJ: Prentice-Hall.

Grey, M. (1985). Return from death: An exploration of the near-death experience. London, England: Arkana.

Hayes, E. R., and Waters, L. D. (1989). Interdisciplinary perception of the near-death experience: Implications for professional education and practice. Death Studies, 13, 443-483.

Kellehear, A., and Heaven, P. (1989). Community attitudes towards near-death experiences: An Australian study. Journal of Near-Death Studies, 7, 165-177.

Kellehear, A., Heaven, P., and Gao, J. (1990). Community attitudes toward near-death experiences: A Chinese study. Journal of Near-Death Studies, 8, 163-173.

Moody, R. A., Jr. (1975). Life after life. Covington, GA: Mockingbird Books. 
Moore, L. H. (1994). An assessment of physicians' knowledge of and attitudes toward the near-death experience. Journal of Near-Death Studies, 13, 91-102.

Morse, M. L., and Perry, P. (1992). Transformed by the light: The powerful effect of near-death experiences on people's lives. New York, NY: Villard Books.

Orne, M. T. (1962). On the social psychology of the psychological experiment: With particular reference to demand characteristics and their implications. American Psychologist, 17, 776-783.

Orne, R. M. (1986). Nurses' views of NDEs. American Journal of Nursing, 86, 419-420.

Ring, K. (1980). Life at death: A scientific investigation of the near-death experience. New York, NY: Coward, McCann and Geoghegan.

Ring, K. (1984). Heading toward omega: In search of the meaning of the near-death experience. New York, NY: William Morrow.

Ring, K. (1992). The omega project: Near-death experiences, UFO encounters, and mind at large. New York, NY: William Morrow.

Ring, K, and Rosing, C. J. (1990). The omega project: An empirical study of the NDEprone personality. Journal of Near-Death Studies, 8, 211-239.

Rogo, D. S. (1986). Life after death: The case for survival of bodily death. London, England: Aquarian Press.

Royse, D. (1985). The near-death experience: A survey of clergy's attitudes and knowledge. Journal of Pastoral Care, 39, 31-42.

Sutherland, C. (1992). Thansformed by the light: Life after near-death experiences. Sydney, Australia: Bantam.

Talbot, M. (1991). The holographic universe. San Francisco, CA: HarperCollins.

Tiberi, E. (1993). Extrasomatic emotions. Journal of Near-Death Studies, 11, 149-170.

Walker, B.A., and Russell, R.D. (1989). Assessing psychologists' knowledge and attitudes toward near-death phenomena. Journal of Near-Death Studies, 8, 103-110. 